\title{
Когнитивная педагогика
}

\section{УДК 378}

\section{Современные аспекты культуросообразного процесса обучения и воспитания в университете в контексте социо-когнитивного подхода}

\section{Modern aspects of the culturally related process of teaching and education at the university in the context of the socio-cognitive approach}

Стукалова О.В., ФГБНУ «Институт педагогики, психологии и сочиальных проблем», Благотворительный фонд содействия развитию социально-культурных инициатив и попечительства «Образ жизни», stukalova@obrazfund.ru

Stukalova O., Institute of Pedagogy, Psychology and Social Problems, Lifestyle Charitable Foundation for Promotion of Social and Cultural Initiatives and Guardianship, stukalova@obrazfund.ru

DOI: $10.51379 / \mathrm{KPJ} .2021 .150 .6 .002$

Статья выполнена по государственному заданию № 0N599-2021-0004 «Проблема современной методологии изучения формирования и развития человека в эпоху цифровизации».

Ключевые слова: сочио-когнитивный подход, культуросообразное воспитание, культурная идентификация, включенное познание, поликультурное пространство.

Keywords: socio-cognitive approach, culture-related upbringing, cultural identification, included cognition, multicultural space.

Аннотация. В статье представлены аргументы важнейшей концептуальной позиции социо-когнитивного подхода, которая основа на представлениях о том, что в культуросообразном процессе обучения и воспитания современный человек, сохраняя свою культурную идентичность, имеет и развитье качества адаптивности к самореализации в глобальном мире. Описана и прокомментирована матрица, отражающая особенности освоения иченностей в современном поликультурном пространстве. Определень наиболее значимые аспекты культуросообразного процесса обучения и воспитания в университете, включая формирование комплекса внешних и внутренних условий, определяющихх естественную позитивную культурную идентификацию студентов, культуросообразное воспитание студентов, выстраивание структуры образовательного процесса с опорой на поддержку в студентах мотивированного включенного познания, моделирование корпоративной академической культуры и профессионального поведения, расширение гуманитарного ядра содержания образования.

Abstract. The article presents the arguments of the most important conceptual position of the socio-cognitive approach, which is based on the idea that in a culturally consistent process of education and teaching, a modern person, while maintaining cultural identity, also has developed qualities of adaptability to self-realization in the global world. Described and commented on the matrix of mastering the totality of values in the modern multicultural space. The most significant aspects of the culturally related process of teaching and education at the university have been identified, including the complex of external and internal conditions development that determine the natural positive cultural identification of students, culturally related education of students, building the structure of the educational process based on support in students of motivated included cognition, modeling corporate academic culture and professional behavior, expanding the humanitarian core of the content of education.

«Обучай культуросообразно! ...В воспитании необходимо принимать во внимание условия места и времени, в которых родился человек или предстоит ему жить, одним словом - всю современную культуру в широком и всеобъемлющем смысле слова, в особенности культуру страны, являющейся родиной ученика». Адольф Дистервег [1, с. 189-190]. 
Введение. Представления о значении культуросообразности в организации образования имеют глубокие корни в психологопедагогической и философской литературе, начиная с античности. К вопросам потенциала этого принципа обращались и выдающиеся педагоги прошлого (А. Дистервег, К.Д. Ушинский и др.), и современные исследователи (В.А. Сластенин, И.Ф. Исаев, Е.Н. Шиянов, Н. Б Крылова, Б.П. Юсов и др.).

В Педагогическом словаре Г.М. Коджаспировой дается следующее определение принципа культуросообразности

«максимальное использование в воспитании и образовании культуры той среды, нации, общества, страны, региона, в которой находится конкретное учебное заведение» [2].

Казалось бы, столь ясный, не требующий дополнительного формулирования аргументов принцип работы с обучающимися и организации образовательного процесса должен быть фундаментально утвержден и укоренен в современном образовании. Между тем, наблюдение и анализ опыта деятельности организаций высшего образования доказывают, что в их работе этот принцип весьма размыт, реализуется непоследовательно и без понимания его возможностей.

Среди причин, по которым современную парадигму высшего образования (да и не только высшего) мы можем назвать несоответствующей принципу культуросообразности, прежде всего надо выделить: 1) доминирование рациональнологического подхода в методике преподавания; 2) девальвацию ценностей гуманитарного познания [3]; 3) формализацию оценки качества образования, когда уровень освоения знаний не связывается с культурным опытом студента, не выявляется степень интериоризации ценностей профессионального становления в университете и получения знаний как фундамента последующей самореализации; 4) отсутствие осознанности и мотивации студентов к освоению культурологических дисциплин, которые практически ни для какой специализации не являются профильными, что приводит к пониманию этих предметов как «ненужных», «бесполезных», не влияющих на дальнейшую успешность в профессии и проч. [4].

В целом, можно констатировать, что принцип культуросообразности в современном высшем образовании зачастую подменяется заучиванием фактов историко-культурного характера, что не обеспечивает необходимую естественность подлинного погружения в культуру, ее ценности, традиции.
Цель статьи. Определить сущностные аспекты культуросообразного процесса обучения и воспитания в университете, раскрыв содержание комплекса внешних и внутренних условий его реализации.

Методология исследования. В рамках социокогнитивного подхода мы предлагаем создание парадигмы образования, которая использует достижения гуманитарного знания и при этом формирует собственные знания и закономерности через системные когнитивные интерпретации с учетом всех особенностей образовательных организаций, образовательных процессов и педагогических взаимодействий, направленных на обучение, воспитание и развитие Homo de futuro (человека будущего). Данная парадигма закладывает основы и определяет механизмы проектирования новой среды организации высшего образования. Ее компонентами становятся «культура - социальный заказ - заказ личности - образование» [5]. Данная парадигма позволяет структурировать образовательный процесс и требуемые для него условия, направленные на развитие универсальных социальных качеств личности студента значимые для его профессии [6].

Остановимся на ряде ключевых положений методологии социо-когнитивного подхода.

Методология социо-когнитивного подхода опирается на представления о неразделимости личностного и профессионального становления, в целом, определяющего процесса для раскрытия творческого потенциала, овладения смыслами собственного бытия и окружающего предметного мира [7]. Очевидно, что, исходя из этих представлений, принцип культуросообразности оказывается теснейшим образом переплетен с принципом человекосообразности, т.к. освоение реалий мира, речи, сущности социальных отношений и уклада, жизненного устройства всей картины мира, не может осуществляться вне социума, вне взаимодействия с ним, вне активных и разнообразных поступков, проявлений личности в культуре и, наоборот, культуры в личности.

Пространством этого взаимодействия оказывается педагогически организованный диалог, т.е. общение на высоком смысловом, содержательном, ценностном уровнях.

Здесь можно привести глубочайшее высказывание М.M. Бахтина об общении. Философ называл само бытие человека «глубочайшим общением». По мнению Бахтина, человек всегда существует в пограничье с другими. Даже, смотря внутрь себя, человек «... смотрит в глаза другому и глазами другого. Жить - значит участвовать в диалоге: вопрошать, 
внимать, ответствовать, соглашаться и т.п.» $[8$, c.312]. Именно в педагогически организованном диалоге происходит усвоение важнейших социальных и культурных установок, позволяющих личности продуктивно и максимально мягко адаптироваться к тому или данному социуму. Таким образом, в образовательном процессе необходимо стимулировать среду, порождающую смысловые образования, значимые для личности - это и эстетическая, и развивающая, и информационная среды. Личность считывает смыслы посредством своих когнитивных способностей (в парадигме социо-когнитивного подхода это верхняя граница возможностей познания окружающего мира и его культурных кодов) и эмоциональных реакций. В социо-когнитивном подходе акцент делается и на влияние профессии, в которой самореализуется личность. Это уже нижняя граница возможностей познания. Выделенные параметры условны, но их важно учитывать при проектировании образовательного процесса и системы педагогического воздействия. В данной системе можно выделить несколько аспектов: индивидуализация, диверсификация образовательных траекторий, гибкая маршрутизация каждого студента (механизм обеспечения индивидуализации), сужение субъективности оценки профессиональной готовности студента, адресная поддержка культуротворческих проявлений.

Подчеркнем: культуротворчество - это не участие в танцевальной студии и не проведение дискуссий на ту или иную культурологическую тему. Культуротворчество предполагает постоянный нравственный выбор поступка, сопряжение себя с культурой, что выражается и в эстетическом отношении к миру, и в выработке определенного жизненного кредо, и в поведении, и в ценностях, на которые опирается человек.

В контексте культуротворчества любой поступок, любое высказывание, любой выбор приобретают коннотации уникальности, в силу принадлежности к неповторимой и не воспроизводимой личности, личности, которая не может быть никем замещена («не люди умирают, а миры...»- Е.А. Евтушенко).

Безусловно, осознание культуротворческой уникальности должно быть неотъемлемо от такого же сильного ощущения уникальности Другого, по крайней мер, его права на эту уникальность. Все это в полной мере относится и к культуре, и шире - культурам. Осознание права на уникальность другой культуры порождает интерес к ней, готовность к погружению, к осмыслению путей, по которым данная культура выстраивает себя в данном географическом и климатическом ландшафте.

Что происходит с личностью, проходящей профессиональную подготовку в культуросообразном процессе университетского образования?

Погружаясь в свою культуру наряду с другими культурами, студент выстраивает проекцию своего образа - и образа «Я» и образа «Я-профессионала». Данная проекция включает и образ Другого человека, и образ Другой культуры как равноценных в отношении к себе. Все это помогает глубоко понять, что источник жизни находится не только в воле человека, в его желаниях и эмоциональных реакциях, но и в окружающих, в культуре народа, ее своеобразии.

M.M. Бахтин применяет для этого процесса термин «вненаходимость» [8, с.7] - понятие, вызывающее острые дискуссии в научной среде и у самых авторитетных комментаторов наследия великого мыслителя [9]. Вненаходимость опорный термин для интерпретации подлинно духовного диалога, обладающего открытой межличностной природой.

В таком диалоге человек входит в бытие, как в мир, пульсирующий разными смыслами, наполненный разными выборами, динамичной коммуникацией, сложной для существования, но одновременно единственно возможной для духовного возвышения, для целостного развития.

Таким образом, методологические положения социо-когнитивного подхода направляют и теоретиков, и практиков педагогики на создание условия для естественного содержательного и гибкого межкультурного диалога, в высшем смысле способного научить будущего специалиста быть беспристрастным, объективным, конструктивным и принципиальным.

Основные характеристики реализации принцииа культуросообразности в выстем образовании.

В контексте парадигмы социо-когнитивного подхода, можно выделить следующие основные характеристики культуросообразного процесса обучения и воспитания: опора на общечеловеческие гуманитарные ценности; изучение особенностей этнической и региональной культуры в толерантном ключе; приобщение к различным пластам культуры.

Bce это, в совокупности, позволяет сформировать целеполагание и разработать механизмы культуросообразного процесса обучения и воспитания - при этом учитывать и контекст социо-когнитивного подхода: «теоретико-методологической стратегии, 
детерминирующей и развивающей смысловые образования, и ценностные преобразования личности с целью формирования ее человекообразующих и социальных качеств в процессе социокультурного взаимодействия акторов высшего образования» [10].

Как уже подчеркивалось выше, данный подход постоянно акцентирует внимание на диалогизации процесса взаимодействия субъектов образования с помощью создания особой среды, в которой происходит вдумчивый структурированный и педагогически организованный поиск личных смыслов в любой деятельности [11].

Pезультаты. Что мы, исходя из позиций социо-когнитивного подхода, считаем сверхзадачей культуросообразного процесса обучения и воспитания?

Сформулируем это так: становление целостной открытой культурной идентичности личности, осуществляемое в поликультурном пространстве, направленное на интериоризацию принятых в данной культуре норм, ценностей, традиций и стиля социализации, с одной стороны, a c другой - поддерживающее развитие в личности открытость к освоению ценностей и норм иных национальных культур и их специфических особенностей. Не случайно Н.Б. Крылова [12] подчеркивает, что культуросообразность отражает соотнесенность образования с культурой как множеством социальных пространств. Важно также обеспечить и включенность образования в культурные процессы современности.

Очевидно, что в культуросообразном процессе обучения и воспитания современный человек, сохраняя свою культурную идентичность, имеет и развитые качества адаптивности к самореализации в глобальном мире.

Наглядно матрицу такого освоения базовых характеристик разных культур можно представить, с точки зрения автора, см. рисунок 1:

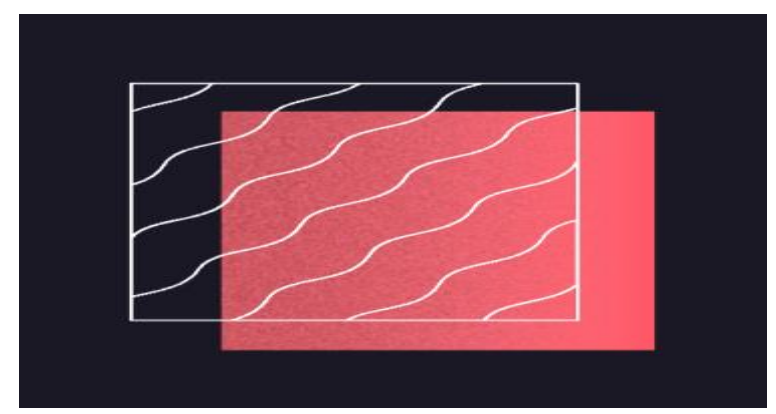

Рисунок 1. - Матрица освоения в современном поликультурном пространстве национальньх, религиозньх, культурньх, бытовых, семейных традиций, правовых обычаев, духовно-нравственных иченностей Автор: Стукалова O.B.

Базовый фундамент - духовно-нравственная, материальная, экономическая, политическая, бытовая и т.д. культура общества (общечеловеческие ценности и представления о существовании личности).

Национальный (этнический) пласт - уклад жизни того или иного социума в определенный период времени, на территории данного региона, существующий в рамках принятого обществом государственного законодательства.

Личная культура, готовность к самореализации, принципы и кредо, установки, нравственная позиция - все, что определяет отношение человека к самому себе, к людям, к социуму, к исторической памяти, к ценности образования, к природе.

В данном случае следует согласиться с современным исследователем О.В. Гукаленко в том, что «культуросообразность предусматривает поворот всех компонентов воспитательного процесса к человеку как к творцу и субъекту, способному к личностному саморазвитию, раскрывает основы взаимосвязи образования и культуры, предусматривает освоение культуры как системы ценностей в контексте развития ребёнка и становления его как творческой личности - человека культурного. Культуросообразность обусловливает отношения между воспитанием и культурой как средой, питающей личность» [13].

Данные идеи вполне можно проецировать на образовательный процесс в университетах. Между тем, несмотря на то, что в научной среде идеи культуросообразного построения содержания высшего образования признаны и имеют теоретическую аргументацию, в реальной практике очевидна недостаточность дидактического и методического инструментария, обеспечивающего его реализацию. 
Чем это обусловлено?

- интенсивными, можно даже сказать, лавинообразными социокультурных условий,

- тотальным влиянием цифровизации, повышением сложности и неопределенности современного мира;

- острыми вызовами современного постиндустриального общества, диктующего педагогам-теоретикам и педагогам-практикам необходимость переосмысления места образования в потребительском мире и массовой культуре.

Культуросообразность сейчас становится все более сложным и многоуровневым понятием, требующим постоянных дополнений, разъяснений, уточнений.

Это весьма ярко раскрывается в образовательном процессе современного университета, существующего в реалиях:

1) поликультурного общества;

2) общества потребления;

3) общества - и глобального, и разъединяющего людей, агрессивно требующего или проявления толерантности и сдерживания своих кардинальных оценок происходящих изменений, нетрадиционных проявлений других людей, или демонстративной манифестации, сопротивления изменениям, нарочитого обращения к традиционной культуре и т.д.

Как реализовать в современной университетской среде принцип культуросообразности? Как сделать опору на этот принцип эффективной?

Остановимся на наиболее значимых аспектах реализации когнитивной парадигмы в целях стремления к культуросообразности образования в практике работы организаций высшего образования.

1. Формирование комплекса внешних и внутренних условий, определяющчи естественную позитивную культурную идентификацию студентов.

В настоящее время мы полагаем, что ко внутренним условиям можно отнести такие проявления, как:

- корпоративная культура университета;

- событийность аудиторной жизни студентов;

- диалог культур, пронизывающий содержание и форматы образовательного процесса.

К внешним условиям мы относим:

- развитие «рынка образовательных услуг»;
- традиционную академическую культуру, основанную на сохранении и приращении ценностей высшего образования, теоретического знаний, индивидуальной исследовательской позиции, принципиальности. Академическая культура предполагает открытость студента к новым формам познания, развитость критического мышления. Безусловно, это означает, что студенты хорошо владеют основными приемами когнитивного освоения мира - анализом, обобщением, абстрагированием, моделированием, сравнением, синтезом, систематизацией и каталогизацией. Качество когнитивной работы тесно взаимосвязано с организационной культурой будущего специалиста, самоконтролем, целеполаганием;

- событийность внеаудиторной жизни студентов.

Пока это гипотеза. Она требует дополнительных исследований, детального рассмотрения в контексте парадигмы социокогнитивного подхода. Так, например, значимым представляется разработка методических рекомендация для активизации аудиторной и внеаудиторной жизни студентов на основе современных форматов цифровой среды. Уже собраны данные по влиянию такого рода событий на профессиональное становление будущих педагогов-магистров ФГБОУ ВО «Ульяновский государственный педагогический университет им. И.Н. Ульянова». Проведенные срезы (2 среза в течение 2020-2021 гг.) уже аргументированно доказывают, что такие события позволяют значительно расширять культурный кругозор студентов, ориентировать их на самообразование и повышение коммуникативных и информационных компетенций.

2. Культуросообразное

воспитание студентов как педагогически организованный процесс взаимодействия субъектов образования.

В данном случае мы говорим о формировании в процессе получения высшего образования и профессиональной подготовки личностной концептосферы студента - будущего специалиста, т.е. речь об обеспечении целостности освоения культурных универсалий, становящих интериоризированными смысловыми установками, которые имеют одновременно и эмоционально ценностные коннотации. В целом, эти установки составляют сущность и личностной, и профессиональной картины мира. Подчеркнем, что в рамках социо-когнитивного подхода, концептосфера понимается, как система речевой культуры, вбирающей в себя не только определенный лексический запас, но и максимальный объем коннотаций, что 
обеспечивает значительное приращение смыслов, аллюзий, многослойных объемов понимания.
3. Вистраивание
сторуктуры

образовательного прочесса с опорой на поддержку в студентах мотивированного включенного познания.

Концептуальной позицией социокогнитивного подхода является представление о том, что в центре образования всегда стоит личность, стремящаяся понять мир через погружение в его многообразие, т.е. открытая к развитию в ситуации поликультурности, насыщенного межкультурного диалога. Таким образом, познание обогащается социальными смыслами [13].

4. Моделирование

корпоративной академической культуры и профессионального поведения.

В условиях образовательного процесса в университете происходит становление специалиста, который глубоко освоил как профессиональные, так и общекультурные компетенции. Это включает в себя:

- готовность к полноценной продуктивной самореализации в поликультурном, быстро меняющемся мире;

- развитую систему ценностей;

- устойчивую мотивацию к постоянному самосовершенствованию и творческому саморазвитию;

- открытость к современным инновационным подходам, обеспечивающим эффективность п профессионально-культурного роста [14].

5. Расиирение гуманитарного ядра содержсания образования.

В данном случае усилия направляются на утверждение мировоззренческих приоритетов гуманистически ориентированных социальных технологий, фасилитацию педагогического общения, когда преподаватель становится посредником между мировым культурным опытом и личным опытом будущего специалиста.

Bce вышеперечисленные аспекты тесно взаимосвязаны и друг с другом. В то же время их определение позволяет: во-первых, более четко понимать приоритетные задачи и характерологические особенности культуросообразного процесса обучения и воспитания в современной организации высшего образования; во-вторых, раскрывать сущность и позиции каждой из «зон ответственности», определяемых для того или иного структурного подразделения университета.

Заключение.

1. Высшее образование находится в стадии перехода к новому качеству, новым принципам организации всего процесса обучения и воспитания будущих специалистов. Bce это требует активизации принципа культуросообразности, который отражается и в содержании, и в выборе форм образования.

2. Культуросообразность, определяя и цели образования и выбор оптимальных условий для реализации всего процесса, позволяет рассматривать профессиональную подготовку через призму «человека будущего», что помогает перспективно оценивать возможности его реализации в ситуации постоянных общественных и экологических вызовов.

3. Современный университет обретает возможности полноценного раскрытия своего потенциала, только сопрягаясь с запросом социума, только переводя форматы обучения на современные социальные направления. Именно в этом случае происходит формирование ответственного и открытого к самосовершенствованию специалиста.

4. Культуросообразное высшее образование, прежде всего, направлено на развитие творческих качеств личности, что предполагает целый комплекс задач - от преодоления информационно-технократического

инфантилизма, сопряженного с известной долей снобизма (не знать, не помнить, не проявлять эрудицию, а «гуглить»), сциентизма, до развития экологического сознания и духовно-нравственной культуры студента, системы ценностей.

5. Важнейшей задачей реализации принципа культуросообразности в рамках социокогнитивного подхода является проектирование культуросообразной среды университета. Обучение в такой среде обеспечивает продуктивное взаимодействие всех субъектов образования с учетом социокультурного опыта каждого, впитывание академических традиций и стимулирование готовности к освоению критического мышления, основ конструктивной дискуссии. В такой среде осуществляется воспитание человека будущего (Homo de futuro) как человека культуры.
1. Дистервег А. Избранные педагогические сочинения / А. Дистервег. - М.: Учпедгиз, 1956. - 374 с.
2. Коджаспирова Г.М., Коджаспиров А.Ю. Педагогический словарь / Г.М. Коджаспирова, А.Ю. Коджаспиров. - М.: Академия, 2000. - 176 с. 
3. Лазарев М.А., Стукалова О.В. Девальвация гуманитарного знания в высшем образовании: пути преодоления кризиса / М.А. Лазарев, О.В. Стукалова // Научно-педагогическое обозрение. Pedagogical Review. 2020. - № 2 (30). - С. 161-171.

4. Горбунов В.И., Евдокимова О.К., Ляпаева Л.В. Интеллигентность студентов регионального технического вуза: постановка вопроса, средства оценивания, пробные результаты / В.И. Горбунов, О.К. Евдокимова, Л.В. Ляпаева // Вестник Чувашского государственного педагогического университета им. И.Я. Яковлева. - 2016. № 1 (89). - C. 82-90.

5. Когнитивная педагогика: учебно-методическое пособие / Р.Х. Гильмеева, А.Р. Камалеева, А.С. Кац, Е.Ю. Левина, В.Ш. Масленикова, Л.Ю. Мухаметзянова, Т.М. Трегубова, Л.А. Шибанкова; под научной редакцией Е.Ю. Левиной. - Казань: «ФГБНУ «Институт педагогики, психологии и социальных проблем», 2020. - 228 с.

6. Гукаленко О.В. Поликультурное образование: теория и практика / О.В. Гукаленко. - Ростов н/Д: Изд-во РГПУ, 2003. - $510 \mathrm{c}$.

7. Сергеев С.Ф. Когнитивная педагогика: особенности научения и образования взрослых / С.Ф. Сергеев // Вестник Северо-восточного федерального университета. 2016. - № 3. - С. 30-35.

8. Бахтин М.М. Эстетика словесного творчества / М.М. Бахтин. - М.: Художественная литература, 1979.

1. Disterweg A. Selected pedagogical works / A. Disterweg. - M.: Uchpedgiz, 1956. - 374 p.

2. Kodzhaspirova G.M., Kodzhaspirov A.Yu. Pedagogical dictionary / G.M. Kodzhaspirova, A. Yu. Kojaspirov. - M.: Academy, 2000. - $176 \mathrm{p}$.

3. Lazarev M.A., Stukalova O.V. Devaluation of humanitarian knowledge in higher education: ways to overcome the crisis / M.A. Lazarev, O. V. Stukalova // Scientific and pedagogical review. Pedagogical Review. 2020. - № 2 (30). - S. 161-171.

4. Gorbunov V.I., Evdokimova O.K., Lyapaeva L.V. Intelligence of students of a regional technical university: formulation of the question, means of assessment, trial results / V.I. Gorbunov, O. K. Evdokimova, L.V. Lyapaeva // Bulletin of the Chuvash State Pedagogical University I. Yakovleva. 2016. - № 1 (89). - S. 82-90.

5. Cognitive pedagogy: teaching aid / R.Kh. Gilmeeva, A.R. Kamaleeva, A.S. Katz, E.Yu. Levin, V. Sh. Maslenikova, L.Yu. Mukhametzyanova, T.M. Tregubova, L.A. Shibankova; under the scientific editorship of E.Yu. Levina. - Kazan: "FGBNU" Institute of Pedagogy, Psychology and Social Problems ", 2020. - 228 p.

6. Gukalenko O.V. Multicultural education: theory and practice / O.V. Gukalenko. - Rostov n / a: Publishing house of the Russian State Pedagogical University, 2003. - 510 p.

7. Sergeev S.F. Cognitive pedagogy: features of learning and education of adults / S.F. Sergeev // Bulletin of the NorthEastern Federal University. - 2016. - № 3. - S. 30-35.
9. Воробьева Л.И. Диалог и коммуникация / Л.И. Воробьева // Московский психотерапевтический журнал. 2006. - № 2. - C. 5-28.

10. Левина Е.Ю., Никулин С.Г. Социо-когнитивный подход в концепции образования взрослых / Е.Ю. Левина, М.Г. Никулин // Профессиональное образование в России и за рубежом. - 2019. - № 4 (36). - С. 106-112.

11. Левина Е.Ю., Мухаметзянова Л.Ю. Развитие Человека знания в ракурсе когнитивной парадигмы / Е.Ю. Левина, Л.Ю. Мухаметзянова // Казанский педагогический журнал. - 2020. - № 3 (140). - С. 8-18.

12. Крылова Н.Б. Очерки понимающей педагогики: книга для молодого педагога, ищущего альтернативного пути в педагогике / Н.Б. Крылова, Е.А. Александрова. М.: Народное образование, 2003.

13. Левина Е.Ю. Когнитивная парадигма управления образовательными системами / Е.Ю. Левина // Педагогический журнал Башкортостана. - 2018. - № 2. - С. 24-30.

14. Коршунова Н.Л. Традиционные и современные трактовки педагогических принципов природосообразности и культуросообразности [Электронный ресурс] / Н.Л. Коршунова // Научнометодический электронный журнал «Концепт». - 2014. - Т. 20. - C. 1406-1410. - Режим доступа: http://ekoncept.ru/2014/54545.htm

\section{References:}

8. Bakhtin M.M. Aesthetics of verbal creativity / M.M. Bakhtin. - M.: Fiction, 1979.

9. Vorobieva L.I. Dialogue and communication / L.I. Vorobyova // Moscow psychotherapeutic journal. - 2006. - № 2. - P. 5-28.

10. Levina E.Yu., Nikulin S.G. Socio-cognitive approach in the concept of adult education / E.Yu. Levina, M.G. Nikulin // Professional education in Russia and abroad. - 2019. - № 4 (36). - S. 106-112.

11. Levina E.Yu., Mukhametzyanova L.Yu. Development of the Human Knowledge in the View of the Cognitive Paradigm / E.Yu. Levina, L.Yu. Mukhametzyanova // Kazan Pedagogical Journal. - 2020. - № 3 (140). - S. 8-18.

12. Krylova N.B. Essays on understanding pedagogy: a book for a young teacher looking for an alternative path in pedagogy / N.B. Krylova, E.A. Alexandrova. - M.: Public education, 2003.

13. Levina E.Yu. Cognitive paradigm of educational systems management / E.Yu. Levina // Pedagogical journal of Bashkortostan. - 2018. - № 2. - P. 24-30.

14. Korshunova N.L. Traditional and modern interpretations of pedagogical principles of conformity to nature and culture [Electronic resource] / N.L. Korshunova // Scientific-methodical electronic journal "Concept". - 2014. - T. 20. - S. 1406-1410. - Access mode: http://ekoncept.ru/2014/54545.htm

13.00.01 - Общая педагогика, история педагогики и образования

\section{Сведения об авторе:}

Стукалова Ольга Вадимовна (г. Москва, Россия), доктор педагогических наук, доцент, ведущий научный сотрудник ФГБНУ «Институт педагогики, психологии и социальных проблем», заместитель директора Благотворительного фонда содействия развитию социально-культурным инициативам и попечительства «Образ жизни», e-mail: stukalova@ obrazfund.ru 